\title{
TILLANDSIA GUATEMALENSIS, UN REGISTRO NUEVO EN LA FLORA DE COSTA RICA
}

\author{
J. Francisco Morales \& Evelio Alfaro \\ Instituto Nacional de Biodiversidad (INBio) \\ Santo Domingo de Heredia, Apto. 22-3100, Costa Rica
}

\begin{abstract}
RESUMEN. Tillandsia guatemalensis, se registra por primera vez en Costa Rica. Se discuten sus relaciones con especies afines y se incluye una clave dicotómica para distinguirlas.

ABSTRACT. Tillandsia guatemalensis, is reported for first time in Costa Rica. Its relationships with other species are discussed. In addition, a key for these species is given.
\end{abstract}

Palabras ClaVe / Key words: Bromeliaceae, Tillandsioideae, Tillandsia guatemalensis, Costa Rica.

La familia Bromeliaceae está representada en Costa Rica con cerca de 210 especies (Morales, 2003b). Algunos géneros como Werauhia presentan un marcado centro de diversidad en Costa Rica, donde muchas especies son endémicas a regiones geográficas muy específicas de la Cordillera de Talamanca. A pesar de que Costa Rica es uno de los países relativamente más explorados en Mesoamérica, sobre todo en relación al estudio de la familia Bromeliaceae, exploraciones e investigaciones de los ultimos 20 años en zonas poco conocidas o totalmente inexploradas han conducido al descubrimiento de novedades en esta familia (Grant \& Morales 1996, Luther 1989, Luther \& Kress 1996, Morales 1999, 2003a). Durante un trabajo de campo en el relativamente desconocido Cerro Echandi, localizado en el suroeste de la Cordillera de Talamanca, una especie desconocida de Tillandsia fue recolectada por uno de los autores (Evelio Alfaro). Esta taxon, perteneciente al subgénero Allardtia, representa el primer registro formal en Costa Rica de T. guatemalensis L.B. Sm. Tal y como comentado en el reciente tratamiento de Bromeliaceae del Manual de las Plantas de Costa Rica (Morales, 2003b), esa especie se había reportado en forma tentativa de una espécimen sin fecha ni localidad exacta colectado por Carl Hoffmann, pero basado en el hecho de que esta colección se quemó en Berlín en 1943 durante la Segunda Guerra Mundial y que se tenían dudas sobre su correcta identificación, no fue incluida en dicho tratamiento.
Tillandsia guatemalensis L. B. Sm., Contr. U.S. Natl. Herb. 29: 281. 1949.

DisTRIBUCIÓN Y HÁBITAT: Esta especie se conoce de México a Panamá, donde crece en bosques muy húmedos, bosques estacionalmente secos y robledales, entre 1300 y $3000 \mathrm{~m}$.

Especímenexaminado: Costa Rica. Puntarenas: Coto Brus, Zona Protectora Las Tablas, cuenca TérrabaSierpe, sendero a Cerro Echandi, 2300 m, 16 mayo 2000 (fl), E. Alfaro 3159 (INB).

Tillandsia guatemalensis pertenece al complejo de T. excelsa Griseb., el cual se caracteriza por presentar taxones con variaciones morfológicas muy grandes, lo que hace su taxonomía algo compleja. Sin embargo, T. guatemalensis se puede reconocer fácilmente por sus brácteas florales más cortas y conspicuamente nervadas. Dado que esta especie no fue incluida en el tratamiento del Manual de Plantas de Costa Rica, se brinda una clave para separar las especies relacionadas (adaptada en parte de Morales 2003b).

\section{Clavedicotómicapara TillaNDSIAGUatemaLENSIS yTAXONESRELACIONADOSEN COSTA RicAy PANAMÁ}

1. Brácteas florales conspicuamente más cortas que los sépalos durante la antesis.

2. Espigas 1-2.5 cm, aglomeradas; vainas pálidas al secar, concoloras con las láminas, a veces levemente matizadas con morado; brácteas primarias pálidas al secar; pétalos lila T. biflora Ruiz \& Pav. 
2. Espigas 3-6 cm, laxamente distribuidas; vainas y brácteas primarias café oscuro al secar; pétalos blancos. $T$. singularis Mez \& Wercklé

1. Brácteas florales más largas o ligeramente más cortas que los sépalos durante la antesis.

3. Brácteas florales patentes a subpatentes respecto al raquis, no adpresas al raquis de las espigas; inflorescencia simple o con 2-3(5) ramos laterales

T. venusta Mez \& Wercklé

3. Brácteas florales ascendentes (respecto al raquis), algo adpresas al raquis de las espigas; inflorescencias siempre compuesta, ramos laterales numerosos.

4. Brácteas florales lisas a casi lisas, si prominentemente nervadas entonces los sépalos más de 1.5 $\mathrm{cm}$ y las ramas laterales de la infl. más largas que las vainas de las brácteas primarias.

5. Ramas de la inflorescencia 1-2(3) fls.; brácteas primarias siempre más largas que los ramos laterales y ocultándolos T. cauliflora Mez \& Wercklé

5. Ramas de la inflorescencia multifloras; brácteas primarias inferiores más largas que los ramos laterales, las superiores más cortas, ramos laterales siempre bien visibles

T. excelsa Griseb.

4. Brácteas florales marcada y regularmente nervadas.

6. Brácteas florales $1.8-3 \mathrm{~cm}$, las primarias siempre tan largas o más largas que los ramos laterales T. leiboldiana Schltdl.

6. Brácteas florales 0.9-1.1(1.7) cm, las primarias inferiores más largas que los ramos laterales T. guatemalensis L. B. Sm.

\section{AgRADECIMIENTOS}

Esta publicación fue financiada por la Asistencia Holandesa para el Desarrollo (NEDA) a través del proyecto "Desarrollo del Conocimiento de la Biodiversidad y Uso Sostenible en Costa Rica" conducido por el Instituto Nacional de Biodiversidad (INBio). Además, la investigación fue posible gracias al convenio de cooperación entre el Ministerio de Ambiente y Energía (MINAE) y el INBio con el fin de completar el Inventario Nacional de Biodiversidad.

\section{LITERATURA CITADA}

Grant, J. R. \& J. F. Morales, 1996. Pitcairnia calcicola (Bromeliaceae), a new species from the tropical dry forest of Costa Rica. Novon 6 (4): 366-369.

Luther, H. 1989. Miscellaneous new taxa of Bromeliaceae VI. Selbyana 11: 54-57.

Luther, H. \& J. Kress. 1996. Two overlooked species of Guzmania (Bromeliaceae) of the species-complex Massangea from Central America. Brittonia 48(1): 9195.

Morales, J. F. 1999. Seis nuevas especies de Vriesea section Xiphion (Bromeliaceae: Tillandsoideae) para Costa Rica. Novon 9: 401-406.

Morales, J. F. 2003a. Nuevas combinaciones y un nuevo nombre en las Bromeliaceas de Costa Rica. Polibotánica 15: 100-103.

Morales, J. F. 2003b. (en prensa). En: B. E. Hammel, M. H. Grayum \& N. Zamora (eds.), Manual de Plantas de Costa Rica. Vol. 2. 